\title{
Factors associated with self-reported number of teeth in a large national cohort of Thai adults
}

Vasoontara Yiengprugsawan ${ }^{1}$, Tewarit Somkotra ${ }^{2 *}$, Matthew Kelly ${ }^{1}$, Sam-ang Seubsman ${ }^{3}$ and Adrian C Sleigh ${ }^{1}$, for the Thai Cohort Study Team

\begin{abstract}
Background: Oral health in later life results from individual's lifelong accumulation of experiences at the personal, community and societal levels. There is little information relating the oral health outcomes to risk factors in Asian middle-income settings such as Thailand today.

Methods: Data derived from a cohort of 87,134 adults enrolled in Sukhothai Thammathirat Open University who completed self-administered questionnaires in 2005. Cohort members are aged between 15 and 87 years and resided throughout Thailand. This is a large study of self-reported number of teeth among Thai adults. Bivariate and multivariate logistic regressions were used to analyse factors associated with self-reported number of teeth.

Results: After adjusting for covariates, being female $(O R=1.28)$, older age $(O R=10.6)$, having low income $(O R=$ 1.45), having lower education ( $O R=1.33)$, and being a lifetime urban resident $(O R=1.37)$ were statistically associated ( $p<0.0001)$ with having less than 20 teeth. In addition, daily soft drink consumptions $(O R=1.41)$, current regular smoking $(O R=1.39)$, a history of not being breastfed as a child $(O R=1.34)$, and mother's lack of education $(O R=1.20)$ contributed significantly to self-reported number of teeth in fully adjusted analyses.
\end{abstract}

Conclusions: This study addresses the gap in knowledge on factors associated with self-reported number of teeth. The promotion of healthy childhoods and adult lifestyles are important public health interventions to increase tooth retention in middle and older age.

\section{Background}

Socio-behavioral and environmental factors have been shown to have epidemiologically important roles in oral health [1-5]. Poor living conditions and limited access to oral health services are important risk factors. In addition, unhealthy lifestyles are substantial determinants of oral health, including poor diet, inadequate oral hygiene, tobacco smoking and alcohol drinking [6,7].

Oral health in later life results from an individual's lifelong accumulation of advantageous and disadvantageous determinant experiences at the personal, community and societal levels. These experiences differ according to gender, race, and various socioeconomic factors such as education, income, and occupation [8]. Several birth cohort studies have shown that socioeconomic inequalities in childhood are associated with

\footnotetext{
* Correspondence: tewarit.s@chula.ac.th

2Department of Community Dentistry, Faculty of Dentistry, Chulalongkorn

University, Bangkok, Thailand

Full list of author information is available at the end of the article
}

differing levels of oral health outcomes in adulthood [9-11]. Good oral health is significantly linked with wellbeing in old age and the importance of oral health among elderly populations has been demonstrated in various settings [12-14]. Therefore, understanding the epidemiology of oral diseases and their socioeconomic patterns across the life course is crucial for determining optimal times for interventions to limit oral disease burden in populations.

According to the Thai National Oral Examination Surveys of 1996, 2001, and 2006, the proportion of the adult population with more than 20 remaining teeth is increasing, which are encouraging for Thailand, but there are still substantial disparities across the country ( $91 \%$ vs $92 \%$ vs $96 \%$ respectively) [15]. The epidemiology of tooth retention and oral health in Asia has mostly been studied in high income countries, especially in Japan and South Korea [16-18]. But there is very little information relating the oral health outcomes to their
C Biomed Central

() 2011 Yiengprugsawan et al; licensee BioMed Central Ltd. This is an Open Access article distributed under the terms of the Creative Commons Attribution License (http://creativecommons.org/licenses/by/2.0), which permits unrestricted use, distribution, and reproduction in any medium, provided the original work is properly cited. 
potential determinants in middle and lower income settings.

To address this knowledge gap on determinants of oral health status, we collected tooth retention data along with detailed information on socio-demographic characteristics, health-risk behaviors and lifecourse history from a large cohort of adults residing throughout Thailand. We have been studying this cohort since 2005 to characterize the health-risk transition as the Thai population moves on from a developing country to a pattern of chronic non-communicable diseases [19-22]. Here we report our analysis of factors associated with self-reported number of teeth among our Thai cohort. This information should help to develop strategies and measures to improve oral health and related wellbeing in the Thai population.

\section{Methods}

\section{Study population and data collection}

In 2005, baseline questionnaires were mailed out to about 200,000 adult students enrolled at Sukhothai Thammathirat Open University (STOU) and 87,134 (44\%) aged 15 to 87 years responded. Details on cohort enrolment and overall methodology have been reported elsewhere [22]. Responding students were similar to other STOU students for age, sex, marital status, income, courses of study and geographical location. Furthermore, the cohort participants were generally similar to the population of Thailand, especially in the 20-39 years age group, for sex ratio, geographical location, and socioeconomic status measured by median income [22]. Participation in the study was voluntary and study leaders reassured participants that their personal responses were confidential. Cohort members were motivated by being fully informed about the purposes of the Thai Health-Risk Transition study and that they could contribute to public health knowledge in Thailand. A periodic newsletter provides information back to cohort members on study progress and follow-up continues [23].

The 2005 20-page baseline questionnaire covered a wide range of topics including demographic, socioeconomic and geographic attributes, health status including self-reported number of teeth, health service use, risk behaviors, injuries, dietary intake, physical activities, and family background. The questionnaire was developed by a multi-disciplinary team of experts in both Thailand and Australia. As far as possible we used standardized validated measures, including those used by the Thai National Statistical Office (e.g. income categories, geographical location, and household assets). There were many iterations and extensive pretesting of back translated Thai versions to ensure face and content validity. Pilot testing preceded the final version.
Here we analyse self-reported number of teeth and relate that to sex; age (3 groups: 15-29 years, 30-49 years, and 50 years and above), monthly income in Thai Baht ( $\leq 3000$; 3001-7000; 7001-10000; and >10000; 40 Baht $\$ 1$ US in 2005), education (highschool, post high school diploma/certificate, university or higher), and household assets (later categorized by total replacement value in Thai Baht into three groups: $<30,000 ; 30,001-$ $60,000$; and $>60,000)$. The household assets included general domestic items such as a microwave oven, electric fan, air conditioner, computer, radio, video/vcd recorder, washing machine, water heater, and telephone).

As well, we determined lifecourse urbanization based on geographic residence now (as an adult member of the cohort) and when aged 12 years-creating the following urbanization categories ('lifetime rural residents'; 'rural-urban migrants'; and 'lifetime urban residents'). The small number of cohort members (4\%) who were categorized as 'urban-rural migrants' were excluded from the analysis so we could concentrate on the main categories that characterized the Thai population today.

\section{Self-reported number of teeth}

Outcome was assessed by the question: "Adults can have up to 32 natural teeth. How many of your own teeth do you have?" Self-reported number of teeth was reported in 4 categories: 'none', '1-5', '6-19', and ' $20+$ ', and was then dichotomized into $<20$ or $\geq 20$.

\section{Other covariates}

Health-risk behavior variables included current regular tobacco smoking (never smoker, ex-smoker, regular smoker), alcohol drinking (regular or not), and soft drink intake (at least daily, or not). Childhood covariates were history of being breastfed as a child recalled by inquiring from relatives (yes, no, or do not know), father's education, and mother's education.

\section{Data processing and statistical analysis}

Data scanning and editing were done using Thai Scandevet, SQL and SPSS software. For analysis we used Stata version 10. Individuals with missing data for analyses presented here were excluded so totals vary a little according to the information available. Missing data usually involved $1 \%$ or less of observations, however, our results were stable given the large size of our dataset. Bivariate analysis was performed followed by stepwise multivariate logistic regression (with p set at < 0.05). Before multivariate analyses were conducted, independent variables were tested for collinearity; no correlation coefficient exceeded 0.52 . Notably, socioeconomic variables (income, education, and household assets) had correlation coefficients lower than 0.34 . 


\section{Ethical considerations}

Ethics approval was obtained from Sukhothai Thammathirat Open University Research and Development Institute (protocol 0522/10) and the Australian National University Human Research Ethics Committee (protocol 2004344). Informed written consent was obtained from all participants.

\section{Results}

Characteristics of the cohort members

There were 87,134 cohort members (Table 1) and $45.3 \%$ were males. Three age groups ranged from 15 to 29 years $(53.6 \%), 30$ to 49 years (43.9\%), 50 years and above $(2.5 \%)$. There were lower proportions of males among the younger group and lower proportions of

Table 1 Characteristics of cohort members by age groups

\begin{tabular}{|c|c|c|c|c|}
\hline \multirow[b]{2}{*}{ Attributes } & \multirow[b]{2}{*}{$N=87,134$} & \multicolumn{3}{|c|}{ Age groups $\%$} \\
\hline & & $\begin{array}{c}\mathrm{n}=46,727 \\
20-29 \text { yrs }\end{array}$ & $\begin{array}{c}\mathrm{n}=38,257 \\
30-49 \text { yrs }\end{array}$ & $\begin{array}{c}n=2,150 \\
50 \text { yrs }+\end{array}$ \\
\hline Overall & & 53.6 & 43.9 & 2.5 \\
\hline \multicolumn{5}{|l|}{ Socio-demographic characteristics* } \\
\hline Males & 45.3 & 37.9 & 52.8 & 71.9 \\
\hline \multicolumn{5}{|l|}{ Marital status } \\
\hline Married & 42.1 & 22.7 & 33.0 & 77.2 \\
\hline \multicolumn{5}{|l|}{ Income (Baht/month) } \\
\hline$<3,000$ & 10.8 & 16.1 & 4.6 & 4.7 \\
\hline $3,001-7,000$ & 30.1 & 41.7 & 17.3 & 8.9 \\
\hline $7,001-10,000$ & 22.7 & 26.1 & 19.5 & 7.3 \\
\hline$>10,000$ & 33.9 & 13.3 & 56.7 & 76.1 \\
\hline \multicolumn{5}{|l|}{ Education (before enrollment at STOU) } \\
\hline Up to high school education & 48.7 & 48.8 & 48.5 & 50.5 \\
\hline Post high school diploma/certificate & 26.9 & 31.3 & 22.2 & 16.4 \\
\hline University degree & 24.1 & 19.7 & 29.0 & 32.6 \\
\hline \multicolumn{5}{|l|}{ Household assets (in Baht) } \\
\hline $0-30,000$ & 40.4 & 50.0 & 30.0 & 20.7 \\
\hline $30,001-60,000$ & 30.5 & 29.4 & 32.1 & 27.5 \\
\hline$>60,000$ & 28.6 & 20.2 & 37.6 & 50.8 \\
\hline \multicolumn{5}{|l|}{ Lifecourse urbanization } \\
\hline Lifetime rural residents & 43.3 & 47.3 & 39.3 & 28.2 \\
\hline Rural-urban residents & 31.5 & 29.9 & 33.3 & 32.6 \\
\hline Lifetime urban residents & 20.0 & 18.2 & 21.0 & 29.5 \\
\hline \multicolumn{5}{|l|}{ Health behaviors } \\
\hline \multicolumn{5}{|l|}{ Smoking } \\
\hline Never smoker & 70.1 & 77.5 & 62.5 & 45.7 \\
\hline Ex smoker & 15.4 & 10.3 & 12.1 & 10.7 \\
\hline A regular smoker & 9.8 & 7.9 & 20.3 & 37.2 \\
\hline \multicolumn{5}{|l|}{ Alcohol drinking } \\
\hline A regular alcohol drinker & 4.8 & 2.9 & 6.9 & 7.9 \\
\hline \multicolumn{5}{|l|}{ Soft drink consumption } \\
\hline Consume soft drink daily & 7.6 & 9.4 & 5.6 & 4.4 \\
\hline \multicolumn{5}{|l|}{ Personal history } \\
\hline \multicolumn{5}{|l|}{ Breastfed as a child } \\
\hline Not breastfed as a child & 7.0 & 7.9 & 6.2 & 6.1 \\
\hline \multicolumn{5}{|l|}{ Father's education } \\
\hline Father no formal education & 5.6 & 4.2 & 6.9 & 13.4 \\
\hline \multicolumn{5}{|l|}{ Mother's education } \\
\hline Mother no formal education & 10.2 & 7.5 & 12.5 & 26.4 \\
\hline
\end{tabular}

*In some categories totals do not add up to $100 \%$ due to missing values. 
females among the older group. Among cohort members, $42.1 \%$ were married and the proportion increased with age. Approximately $11 \%$ of cohort members reported income less than 3,000 Baht and 33.9\% reported income more than 10,000 Baht per month. There was a clear positive trend between age and income. Three groups of lifecourse urbanization were analysed: lifetime rural residents (43.3\%); rural moved to urban areas since age 12 years (31.5\%); and lifetime urban residents (20.0\%).

Regarding health behaviors, 9.8\% reported being a current regular smoker, $4.8 \%$ reported being a current regular alcohol drinker. Both health risk behaviors increase with age (37.2\% regular current smoker among older persons compared to $7.9 \%$ among the youngest group). Daily consumption of carbonated beverage was reported by $7.6 \%$ of the cohort members, $9.4 \%$ among the youngest group compared to $4.4 \%$ among the oldest group.

Not being breastfed as a child was reported by $7.0 \%$, generally a little less in older groups. Parental history of a father with lower than primary education was $4.2 \%$ among the cohort members aged 15 to 29 years old compared to $13.4 \%$ among the cohort members aged 50 years and above. A similar trend was noticed for less than primary education for mothers of younger vs. older cohort members ( $7.5 \%$ vs. $26.4 \%)$

\section{Self-reported number of teeth}

Among cohort members, 3.3\% reported having less than 20 teeth $(2.4 \%$ for $15-29$ year-olds vs. $17.2 \%$ for those aged 50 years or more). The older group consistently reported less than 20 teeth across all other characteristics included in Table 2 where age was the most prominent factor associated with less than 20 teeth. Those in the lowest income group were more likely to report less than 20 teeth compared to the highest income group and this trend increased with age. Across all age groups, lifetime urban residents were more likely than lifetime rural residents to report less than 20 teeth (overall 4.4\% vs $2.9 \%)$.

Self-reported less than 20 teeth was more common among current regular smokers (4.1\% vs. $3.0 \%)$, current regular alcohol drinkers (4.2\% vs. $3.2 \%)$, and cohort members who consumed soft drink daily (4.2\% vs. $3.2 \%)$. Having a history of not being breastfed as a child was associated with less than 20 teeth (4.1\% vs $3.1 \%)$. Those with father's education of less than primary level were also more likely to have less than 20 teeth $(4.5 \%$ vs. $3.2 \%)$.

\section{Factors associated with self-reported number of teeth}

Bivariate and multivariate results of determinants for self-reported number of teeth are shown in Table 3. After adjusting for all covariates accepted by the stepwise multivariate logistic regression model, being female $(O R=1.28)$, older age $(O R=10.6)$, having low income $(\mathrm{OR}=1.45)$, having lower education $(\mathrm{OR}=$ 1.33), and being a lifetime urban resident $(\mathrm{OR}=1.37)$ were all associated with less than 20 teeth.

In addition, daily soft drink consumption $(\mathrm{OR}=1.41)$ and current regular smoking $(\mathrm{OR}=1.39)$ were also positively associated with less than 20 teeth, but there was no statistically significant association to current alcohol drinking after adjusting in the full model. A history of not being breastfed as a child was statistically associated with less than 20 teeth $(\mathrm{OR}=1.34)$. Mother's education (but not the father's) was associated with less than 20 teeth after adjusting for covariates $(\mathrm{OR}=1.20)$.

\section{Discussion}

To our knowledge, this is the first large scale study that assessed the factors associated with self-reported number of teeth among Thai adults. Key findings of our study were being female, of older age, low income, lower education, and being a lifetime urban resident were all strongly associated with less than 20 teeth. In relation to urban or rural residence, we cannot be sure if the self-reported number of teeth reflects differential access to tooth extraction. Formal access to dental care is better in cities but tooth extraction (for pain relief) is more common in rural areas and amongst lower income.

Our study is consistent with previous studies on the role of health-related behaviors, especially tobacco smoking on self-reported number of teeth. A Japanese study found the odds ratios of having more than eight missing teeth was much higher among current smokers compared to males who had never smoked $(\mathrm{OR}=1.67)$ [24]. An Australian ' 45 and Up' cohort study based on over 100,000 participants also showed that current smokers had significantly higher odds of tooth loss compared with never smokers $(\mathrm{OR}=2.51)$ [25].

Our findings that consumption of soft drink or carbonated beverage was strongly associated with selfreported number of teeth among our cohort, confirms previous studies [26-28]. Undesirable oral health behaviors adopted in early years are likely to be sustained throughout life and together with cumulative effects of exposure to other risk factors can lead to poor oral health outcomes in later life.

Our study also showed the influence of certain lifecourse factors such as a history of breastfeeding and maternal education on self-reported number of teeth. A study in New Zealand demonstrated that childhood circumstances have a major influence on oral health in adulthood $[9,10]$. After controlling for childhood oral health, those who were disadvantaged at the age of 5 years had higher levels of dental caries and periodontal 
Table 2 Self-reported number of teeth by attributes of cohort members

\begin{tabular}{|c|c|c|c|c|}
\hline \multirow[t]{2}{*}{ Attributes } & \multicolumn{4}{|c|}{ Less than 20 teeth (\%) } \\
\hline & \multirow[b]{2}{*}{$\mathrm{N}=87,134$} & \multicolumn{3}{|c|}{ Age groups } \\
\hline & & $\begin{array}{c}\mathrm{n}=46,727 \\
20-29 \text { yrs }\end{array}$ & $\begin{array}{c}n=38,257 \\
30-49 \text { yrs }\end{array}$ & $\begin{array}{c}\mathrm{n}=2,150 \\
50 \mathrm{yrs}+\end{array}$ \\
\hline Overall & 3.3 & 2.4 & 3.6 & 17.2 \\
\hline \multicolumn{5}{|l|}{ Socio-demographic characteristics } \\
\hline Males & 3.3 & 2.1 & 3.2 & 17.9 \\
\hline Females & 3.3 & 2.6 & 4.0 & 15.2 \\
\hline \multicolumn{5}{|l|}{ Marital status } \\
\hline Married & 3.6 & 2.0 & 3.5 & 16.5 \\
\hline Non married & 3.0 & 2.5 & 3.8 & 20.0 \\
\hline \multicolumn{5}{|l|}{ Income (Baht/month) } \\
\hline$<3,000$ & 3.8 & 1.6 & 3.5 & 16.7 \\
\hline $3,001-7,000$ & 2.6 & 1.8 & 3.4 & 15.3 \\
\hline $7,001-10,000$ & 3.1 & 1.6 & 3.5 & 16.8 \\
\hline$>10,000$ & 3.5 & 2.0 & 3.3 & 15.3 \\
\hline \multicolumn{5}{|l|}{ Education (before enrollment at STOU) } \\
\hline Up to high school education & 3.6 & 2.7 & 3.7 & 17.9 \\
\hline Post high school diploma/certificate & 3.2 & 2.3 & 4.0 & 20.7 \\
\hline University degree & 2.9 & 1.6 & 3.2 & 14.4 \\
\hline \multicolumn{5}{|l|}{ Household assets (Baht) } \\
\hline $0-30,000$ & 3.1 & 2.1 & 3.7 & 15.1 \\
\hline $30,001-60,000$ & 3.3 & 2.4 & 3.6 & 19.3 \\
\hline$>60,000$ & 3.6 & 2.5 & 3.5 & 19.6 \\
\hline \multicolumn{5}{|l|}{ Lifecourse urbanization } \\
\hline Lifetime rural residents & 2.9 & 2.3 & 3.2 & 16.0 \\
\hline Rural-urban residents & 4.8 & 2.2 & 2.9 & 14.3 \\
\hline Lifetime urban residents & 4.4 & 2.7 & 5.0 & 19.7 \\
\hline \multicolumn{5}{|l|}{ Health behaviors } \\
\hline \multicolumn{5}{|l|}{ Smoking } \\
\hline Never smoker & 3.0 & 2.4 & 3.5 & 14.6 \\
\hline Ex smoker & 3.7 & 2.0 & 3.4 & 17.6 \\
\hline A regular smoker & 4.1 & 2.1 & 4.6 & 27.7 \\
\hline \multicolumn{5}{|l|}{ Alcohol drinking } \\
\hline Not a regular alcohol drinker & 3.2 & 2.4 & 3.6 & 16.5 \\
\hline A regular alcohol drinker & 4.2 & 2.4 & 4.0 & 21.1 \\
\hline \multicolumn{5}{|l|}{ Soft drink consumption } \\
\hline Not consume soft drink daily & 3.2 & 2.3 & 3.5 & 17.0 \\
\hline Consume soft drink daily & 4.2 & 3.5 & 5.0 & 20.2 \\
\hline \multicolumn{5}{|l|}{ Personal history } \\
\hline \multicolumn{5}{|l|}{ Breastfed as a child } \\
\hline Reported breastfed as a child & 3.1 & 2.3 & 3.4 & 16.9 \\
\hline Not breastfed as a child & 4.1 & 3.2 & 5.0 & 17.0 \\
\hline \multicolumn{5}{|l|}{ Father's education } \\
\hline Father no formal education & 4.5 & 2.5 & 4.2 & 21.3 \\
\hline Father primary education and above & 3.2 & 2.4 & 3.6 & 16.4 \\
\hline \multicolumn{5}{|l|}{ Mother's education } \\
\hline Mother no formal education & 4.5 & 2.3 & 4.6 & 18.0 \\
\hline Mother primary education and above & 3.1 & 2.4 & 3.5 & 17.0 \\
\hline
\end{tabular}


Table 3 Factors associated with self report of less than 20 teeth among cohort members

\begin{tabular}{|c|c|c|c|c|}
\hline \multirow[t]{2}{*}{ Attributes } & \multicolumn{2}{|c|}{ Bivariate } & \multicolumn{2}{|c|}{ Stepwise multivariate* } \\
\hline & Odds Ratios & $\mathrm{p}$-value & Odds Ratios & $\mathrm{p}$-value \\
\hline \multicolumn{5}{|l|}{ Socio-demographic characteristics } \\
\hline Males & 1 & & & \\
\hline Females & 1.19 & 0.000 & 1.28 & 0.000 \\
\hline $15-29$ years & 1 & & & \\
\hline 30-49 years & 1.56 & 0.000 & 1.79 & 0.000 \\
\hline $50+$ years & 9.05 & 0.000 & 10.6 & 0.000 \\
\hline Married & 1 & & & \\
\hline Non married & 1.14 & 0.002 & & \\
\hline \multicolumn{5}{|l|}{ Income (Baht/month) } \\
\hline$<3,000$ & 1.48 & 0.000 & 1.45 & 0.000 \\
\hline $3,001-7,000$ & 1.25 & 0.004 & 1.26 & 0.000 \\
\hline $7,001-10,000$ & 0.96 & 0.426 & & \\
\hline$>10,000$ & 1 & & & \\
\hline \multicolumn{5}{|l|}{ Education (before enrollment at STOU) } \\
\hline Up to high school education & 1.38 & 0.000 & 1.33 & 0.000 \\
\hline Post high school diploma/certificate & 1.32 & 0.000 & 1.24 & 0.000 \\
\hline University degree & 1 & & & \\
\hline \multicolumn{5}{|l|}{ Household assets (Baht) } \\
\hline $0-30,000$ & 1.09 & 0.215 & & \\
\hline $30,001-60,000$ & 1.06 & 0.071 & & \\
\hline$>60,000$ & 1 & & & \\
\hline \multicolumn{5}{|l|}{ Lifecourse urbanization } \\
\hline Lifetime rural residents & 1 & & & \\
\hline Rural-urban residents & 0.91 & 0.061 & & \\
\hline Lifetime urban residents & 1.34 & 0.000 & 1.37 & 0.000 \\
\hline \multicolumn{5}{|l|}{ Health behaviors } \\
\hline \multicolumn{5}{|l|}{ Smoking } \\
\hline Never smoker & 1 & & & \\
\hline Ex smoker & 1.17 & 0.010 & & \\
\hline A regular smoker & 1.46 & 0.000 & 1.39 & 0.000 \\
\hline \multicolumn{5}{|l|}{ Alcohol drinking } \\
\hline Not a regular alcohol drinker & 1 & & & \\
\hline A regular alcohol drinker & 1.24 & 0.011 & & \\
\hline \multicolumn{5}{|l|}{ Soft drink consumption } \\
\hline Not consume soft drink daily & 1 & & & \\
\hline Consume soft drink daily & 1.50 & 0.000 & 1.41 & 0.000 \\
\hline \multicolumn{5}{|l|}{ Personal history } \\
\hline \multicolumn{5}{|l|}{ Breastfed as a child } \\
\hline Reported breastfed as a child & 1 & & & \\
\hline Not breastfed as a child & 1.29 & 0.000 & 1.34 & 0.000 \\
\hline \multicolumn{5}{|l|}{ Parental education } \\
\hline Father no formal education & 1.19 & 0.015 & & \\
\hline Father primary education and above & 1 & & & \\
\hline Mother no formal education & 1.18 & 0.003 & 1.20 & 0.005 \\
\hline Mother primary education and above & 1 & & & \\
\hline
\end{tabular}

*Based on multivariate logistic regression using Stata 10 (see Methods). 
disease and were more likely to experience premature tooth loss in adulthood. Hence, the promotion of healthy childhoods is important public health interventions to increase tooth retention in middle and older age.

Thailand has implemented a Universal Coverage Scheme (UCS) for healthcare since 2001 and basic oral healthcare was part of the package $[29,30]$. However, a recent study based on over 30,000 Thai adults aged 15 and 75 years from nationally representative surveys reported that substantial socioeconomic inequality in self-reported oral health status still persisted after the UCS [31,32]. It should be noted that this representative study was carried out only two years after the UCS reached the whole Thai population, meaning that there may not be sufficient time for measurable improvement on oral health status.

It is important to take into account the possible limitations of our study. For example, our cohort members are university educated and therefore results may not be generalized to the Thai population at large. In addition, there could be some possible recall bias in reporting past behaviors, such as being breastfed as a child. Our data presented here were derived from the cross-sectional baseline questionnaire of our study. Longitudinal data will provide more insight into determinants of selfreported number of teeth.

Although, this study relied on self-reported number of teeth it should be noted that this simple measurement is now used in an increasing number of studies and does capture important information on oral health morbidity [33]. Further studies should emphasise some aspects of positive outcomes of oral health and oral health-related quality of life to fill gaps in information concerning oral health outcomes [34].

\section{Conclusion}

This study addresses the gap in knowledge on factors associated with self-reported number of teeth. Major challenges of the future will be to translate knowledge and experiences of oral health promotion and disease prevention into action programs in Thailand. For instance, dental health should be integrated into public health programs targeting chronic diseases. Sustainable oral health improvements in Thailand require an approach which addresses the underlying determinants of oral health. Many of those determinants have been noted in this study, including sociodemographic risk factors and adverse health behaviours.

\section{Acknowledgements and Funding}

This study was supported by the International Collaborative Research Grants Scheme with joint grants from the Wellcome Trust UK (GR071587MA) and the Australian NHMRC (268055), and as a global health grant from the
NHMRC (585426). We thank the staff at Sukhothai Thammathirat Open University (STOU) who assisted with student contact and the STOU students who are participating in the cohort study. We also thank Dr Bandit Thinkamrop and his team from Khon Kaen University for guiding us successfully through the complex data processing. We would like to thank the two reviewers for their comments which helped to improve the manuscript.

The Thai Cohort Study Team

Thailand: Jaruwan Chokhanapitak, Chaiyun Churewong, Suttanit

Hounthasarn, Suwanee Khamman, Daoruang Pandee, Suttinan Pangsap, Tippawan Prapamontol, Janya Puengson, Yodyiam Sangrattanakul, Sam-ang Seubsman, Boonchai Somboonsook, Nintita Sripaiboonkij, Pathumvadee Somsamai, Duangkae Vilainerun, Wanee Wimonwattanaphan.

Australia: Chris Bain, Emily Banks, Cathy Banwell, Bruce Caldwell, Gordon Carmichael, Tarie Dellora, Jane Dixon, Sharon Friel, David Harley, Matthew Kelly, Tord Kjellstrom, Lynette Lim, Anthony McMichael, Tanya Mark, Adrian Sleigh, Lyndall Strazdins, Vasoontara Yiengprugsawan.

\section{Author details}

${ }^{1}$ National Centre for Epidemiology and Population Health, The Australian National University, Canberra, Australia. ${ }^{2}$ Department of Community Dentistry, Faculty of Dentistry, Chulalongkorn University, Bangkok, Thailand. ${ }^{3}$ School of Human Ecology, Sukhothai Thammathirat Open University, Nonthaburi, Thailand.

\section{Authors' contributions}

VY and TS conceptualised, analysed and drafted the manuscript. MK provided editorial support. SS and AS designed the project and provided comments. The Thai Cohort Study Team contributed to various stages of the project. All authors read and approved the final manuscript.

\section{Competing interests}

The authors declare that they have no competing interests.

Received: 17 January 2011 Accepted: 24 November 2011

Published: 24 November 2011

\section{References}

1. Pearce MS, Steele JG, Mason J, Walls AW, Parker L: Do circumstances in early life contribute to tooth retention in middle age? J Dent Res 2004, 83(7):562-566.

2. Kwan S, Petersen PE: Oral health: equity and social determinants. In Equity, social determinants and public health programmes. Edited by: Blas E, Kurup AS. Geneva: World Health Organization; 2010:159-176.

3. Sanders AE, Spencer AJ: Childhood circumstances, psychosocial factors and the social impact of adult oral health. Community Dent Oral Epidemiol 2005, 33(5):370-377.

4. Shearer DM, Thomson WM: Intergenerational continuity in oral health: a review. Community Dent Oral Epidemiol 2010, 38(6):479-486.

5. Watt RG: From victim blaming to upstream action: tackling the social determinants of oral health inequalities. Community Dent Oral Epidemiol 2007, 35(1):1-11

6. Petersen PE, Bourgeois D, Ogawa H, Estupinan-Day S, Ndiaye C: The global burden of oral diseases and risks to oral health. Bull World Health Organ 2005, 83(9):661-669.

7. WHO: The World Oral Health Report: Continuous improvement of oral health in the 21st century - the approach of the WHO Global Oral Health Programme Geneva: World Health Organization; 2003.

8. Nicolau B, Marcenes W, Bartley M, Sheiham A: Associations between socioeconomic circumstances at two stages of life and adolescents' oral health status. J Public Health Dent 2005, 65(1):14-20.

9. Poulton R, Caspi A, Milne BJ, Thomson WM, Taylor A, Sears MR, Moffitt TE: Association between children's experience of socioeconomic disadvantage and adult health: a life-course study. Lancet 2002, 360(9346):1640-1645.

10. Thomson WM, Poulton R, Milne BJ, Caspi A, Broughton JR, Ayers KM: Socioeconomic inequalities in oral health in childhood and adulthood in a birth cohort. Community Dent Oral Epidemiol 2004, 32(5):345-353.

11. Melchior M, Moffitt TE, Milne BJ, Poulton R, Caspi A: Why do children from socioeconomically disadvantaged families suffer from poor health when 
they reach adulthood? A life-course study. Am J Epidemiol 2007, 166(8):966-974.

12. Barmes DE: Public policy on oral health and old age: a global view. $J$ Public Health Dent 2000, 60(4):335-337.

13. Petersen PE, Yamamoto T: Improving the oral health of older people: the approach of the WHO Global Oral Health Programme. Community Dent Oral Epidemiol 2005, 33(2):81-92.

14. Lamster IB, Lalla E, Borgnakke WS, Taylor GW: The relationship between oral health and diabetes mellitus. J Am Dent Assoc 2008, 139(Suppl):19S-24S.

15. Division of Dental Public Health - Thai Ministry of Public Health: The 6th National Oral Health Survey in Thailand 2006-2007. Bangkok: The Veteran Organization Publishing; 2008.

16. Aida J, Hanibuchi T, Nakade M, Hirai H, Osaka K, Kondo K: The different effects of vertical social capital and horizontal social capital on dental status: a multilevel analysis. Soc Sci Med 2009, 69(4):512-518.

17. Jung YM, Shin DS: Oral health, nutrition, and oral health-related quality of life among Korean older adults. J Gerontol Nurs 2008, 34(10):28-35.

18. Akifusa S, Soh I, Ansai T, Hamasaki T, Takata Y, Yohida A, Fukuhara M, Sonoki $\mathrm{K}$, Takehara T: Relationship of number of remaining teeth to health-related quality of life in community-dwelling elderly. Gerodontology 2005, 22(2):91-97.

19. Pachanee CA, Lim L, Bain C, Wibulpolprasert S, Seubsman SA, Sleigh AC: Smoking behavior among 84,315 Open University students in Thailand. Asia Pac J Public Health 2010, 23(4):544-554

20. Yiengprugsawan V, Somkotra T, Seubsman SA, Sleigh AC: Oral HealthRelated Quality of Life among a large national cohort of 87,134 Thai adults. Health Qual Life Outcomes 2011, 9(1):42.

21. Jordan S, Lim L, Vilainerun D, Banks E, Sripaiboonkij N, Seubsman SA, Sleigh A, Bain C: Breast cancer in the Thai Cohort Study: an exploratory case-control analysis. Breast 2009, 18(5):299-303.

22. Sleigh AC, Seubsman SA, Bain C: Cohort profile: The Thai Cohort of 87,134 Open University students. Int J Epidemiol 2008, 37(2):266-272.

23. Yiengprugsawan V, Seubsman S, Lim L, Sleigh A: Use and foregone health services among a cohort of 87,134 adult open university students in Thailand. Southeast Asian J Trop Med Public Health 2009, 40(6):1347-1358.

24. Yanagisawa T, Ueno M, Shinada K, Ohara S, Wright FA, Kawaguchi Y: Relationship of smoking and smoking cessation with oral health status in Japanese men. J Periodontal Res 2010, 45(2):277-283.

25. Arora M, Schwarz E, Sivaneswaran S, Banks E: Cigarette smoking and tooth loss in a cohort of older Australians: the 45 and up study. J Am Dent Assoc 2010, 141(10):1242-1249.

26. Heller KE, Burt BA, Eklund SA: Sugared soda consumption and dental caries in the United States. J Dent Res 2001, 80(10):1949-1953.

27. Sheiham A: Dietary effects on dental diseases. Public Health Nutr 2001, 4(2B):569-591.

28. Ismail Al, Tanzer JM, Dingle JL: Current trends of sugar consumption in developing societies. Community Dent Oral Epidemiol 1997, 25(6):438-443.

29. Yiengprugsawan V, Carmichael G, Lim LY, Seubsman S, Sleigh A: Explanation of inequality in utilization of ambulatory care before and after universal health insurance in Thailand. Health Policy Plan 2011, 26(2):105-114.

30. Tangcharoensathien $V$, Jongudomsuk $P$, (Eds): From policy to implementation: historical events during 2001-2004 of universal coverage in Thailand Nonthaburi: National Health Security Office; 2004.

31. Somkotra T: Socioeconomic inequality in self-reported oral health status: the experience of Thailand after implementation of the universal coverage policy. Community Dent Health 2011, 28(2):136-142.

32. Somkotra T, Detsomboonrat P: Is there equity in oral healthcare utilization: experience after achieving Universal Coverage. Community Dent Oral Epidemiol 2009, 37(1):85-96.

33. Bernabe $E$, Marcenes W: Income inequality and tooth loss in the United States. J Dent Res 2011, 90(6):724-729.

34. Locker D, Allen F: What do measures of 'oral health-related quality of life' measure? Community Dent Oral Epidemiol 2007, 35(6):401-411.

\section{Pre-publication history}

The pre-publication history for this paper can be accessed here:

http://www.biomedcentral.com/1472-6831/11/31/prepub doi:10.1186/1472-6831-11-31

Cite this article as: Yiengprugsawan et al:: Factors associated with selfreported number of teeth in a large national cohort of Thai adults. BMC Oral Health 2011 11:31.

\section{Submit your next manuscript to BioMed Central and take full advantage of:}

- Convenient online submission

- Thorough peer review

- No space constraints or color figure charges

- Immediate publication on acceptance

- Inclusion in PubMed, CAS, Scopus and Google Scholar

- Research which is freely available for redistribution

Submit your manuscript at www.biomedcentral.com/submit
Biomed Central 